\title{
REPARO A QUENTE NO REGENERADOR DO ALTO- FORNO 3 DA USIMINAS - USINA DE IPATINGA*
}

\author{
Eustáquio Vieira Junior ${ }^{1}$ \\ Mauro Vivaldino. Fernandes ${ }^{2}$ \\ Claudiney de Freitas Oliveira ${ }^{3}$
}

\section{Resumo}

O Alto-Forno 3 da Usiminas, em Ipatinga, possui três regeneradores de câmara de combustão interna e passou por sua última reforma em 1999. Nessa reforma, não foram realizadas alterações de projeto nos regeneradores, sendo somente substituídas as fiadas superiores da parede de partição entre as câmaras de combustão e de regeneração e do checker, que se encontravam desgastadas. No decorrer de 2007 e nos anos seguintes, verificou-se a queda de tijolos refratários na região localizada acima do queimador cerâmico do Regenerador 7 . Durante 0 processo investigativo, adotou-se a inspeção por videoendoscopia a partir de 2010. Face à deterioração da região onde se concentravam as quedas de tijolos e à postergação da reforma do Alto-Forno 3, decidiu-se pelo reparo a quente deste regenerador. O trabalho apresenta o histórico das ocorrências no Regenerador 7, as intervenções anteriores ao reparo, o planejamento e os resultados obtidos a partir da operação com dois regeneradores e o desempenho dos regeneradores do AltoForno 3 após o reparo a quente no Regenerador 7, mostrando a eficiência do reparo realizado.

Palavras-chave: Alto-forno; Regenerador; Reparo a quente.

\section{HOT REPAIR IN HOT STOVE OF USIMINAS'S BLAST FURNACE\#3 - IPATINGA PLANT}

\begin{abstract}
Usiminas Blast Furnace\#3, in Ipatinga, has three internal chamber hot stoves, that were relined in 1999. At that time, there were no modification on the hot stoves original design, only the superior layers of partition wall between the regeneration and combustion chambers and the superior layers of checker were changed. In 2007 it was noted that the refractory bricks on the region above the ceramic burner of hot stove\#7 were falling. Since then investigations were realized, using the video endoscopy technique after 2010. The decision to repair this equipment was after the region increase his damage and the postponed of the Blast Furnace\#3 relining. This report presents the hot stove situation, the refractory maintenance before the repair, the planning and results of operation with two hot stoves and also the Blast Furnace\#3's performance after the hot stove\#7 high temperature repairs.
\end{abstract}

Keywords: Blast furnace; Hot stove; Hot repair.

1 Membro ABM, Engenheiro Metalurgista, Gerência Técnica de Redução; Usiminas, Ipatinga, MG, Brasil.

2 Membro ABM, Engenheiro Metalurgista, M.Sc., Gerência Técnica de Redução; Usiminas, Ipatinga, MG, Brasil.

3 Assistente Industrial, Gerência de Alto-Forno 3; Usiminas, Ipatinga, MG, Brasil.

\footnotetext{
* Contribuição técnica ao 44ำ Seminário de Redução de Minério de Ferro e Matérias-primas, 15ํ Simpósio Brasileiro de Minério de Ferro e $2^{\circ}$ Simpósio Brasileiro de Aglomeração de Minério de Ferro, 15 a 18 de setembro de 2014, Belo Horizonte, MG, Brasil.
} 


\section{INTRODUÇÃO}

A usina siderúrgica da Usiminas em Ipatinga-MG tem três altos-fornos, o Alto-Forno 3 é responsável por aproximadamente $70 \%$ da produção de gusa da planta, os Altos-Fornos 1 e 2, têm capacidades similares e são responsáveis pelo restante da produção. O Alto-Forno 3 foi reformado em 1999, quando foi instalado o sistema de refrigeração por stave-coolers (corpo e cadinho) e não foram realizadas alterações de projeto nos seus três regeneradores, sendo somente substituídas as fiadas superiores da parede de partição entre as câmaras de combustão e de regeneração e dos checker, que se encontravam desgastadas.

Inicialmente, as reformas [1] dos altos-fornos 1, 2 e 3 estavam previstas em 2013, 2014 e 2016 respectivamente. Contudo, no final de 2008, devido à crise econômica mundial, foi necessária a redução drástica da produção de gusa. Na usina de Ipatinga ocorreu o abafamento dos Altos-Fornos 1 e 2, e redução drástica da produção de gusa do Alto-Forno 3. Em função disso e em virtude da restrição de investimentos, muitas ações estão em prática para postergar as reformas destes equipamentos.

No presente trabalho é apresentado o histórico das ocorrências no Regenerador 7 do Alto-Forno 3, as intervenções anteriores ao reparo, o planejamento e os resultados obtidos a partir da operação com dois regeneradores. Apresenta também o desempenho dos Regeneradores 8 e 9 do Alto-Forno 3 após o reparo a quente no Regenerador 7.

As principais características do Alto-Forno 3 da Usiminas de Ipatinga são mostradas na tabela 1 e os principais resultados operacionais de suas campanhas são mostrados na tabela 2 .

Tabela 1. Principais características do Alto-Forno 3 da Usiminas Ipatinga

\begin{tabular}{c|c|c}
\hline Itens & Unidade & AF3 \\
\hline Volume interno & $\mathrm{m}^{3}$ & 3163 \\
\hline Volume de trabalho & $\mathrm{m}^{3}$ & 2950 \\
\hline Diâmetro do cadinho & $\mathrm{m}$ & 12,2 \\
\hline Capacidade de produção & t/dia & 8200 \\
\hline Número de ventaneiras & - & 30 \\
\hline Número de furo de gusa & - & 3 \\
\hline Topo & - & Duplo cone \\
\hline Sistema de granulação & - & INBA \\
\hline Temperatura máxima de sopro & $\circ \mathrm{C}$ & 1200 \\
\hline $\begin{array}{c}\text { Sistema de refrigeração cuba, } \\
\text { ventre, rampa e cadinho }\end{array}$ & - & Stave-coolers \\
\hline Início da campanha atual & - & $29 / 10 / 1999$ \\
\hline
\end{tabular}

Tabela 2. Campanhas do Alto-Forno 3 da Usiminas Ipatinga

\begin{tabular}{|c|c|c|c|c|c|c|c|c|}
\hline \multirow{2}{*}{ CAMP* $^{*}$} & BLOW IN & BLOW OUT & \multirow{2}{*}{$\frac{\text { PRODUTIVIDADE }}{\mathrm{t} / \mathrm{d} / \mathrm{m}^{3}}$} & CR & ÓLEO & $\mathrm{PCl}$ & GN & FR \\
\hline & \multicolumn{2}{|c|}{ D A T A } & & \multicolumn{5}{|c|}{ kg/t } \\
\hline \multicolumn{9}{|c|}{ ALTO - FORNO 3} \\
\hline $1^{\underline{a}}$ & |20/12/1974 & $07 / 0$ & 1,750 & 479,0 & 34,0 & - & - & 513,0 \\
\hline $2^{\underline{a}}$ & $07 / 1$ & $08 /($ & 1 , & 503,0 & - & - & - & 503,0 \\
\hline $3^{\mathrm{a}}$ & 03/07/1987 & $12 / 06$ & 2,423 & 457,2 & - & 44,9 & - & 502,1 \\
\hline $4^{\mathrm{a}}$ & 29/10/1999 & $30 / 04 / 2012$ & 2,374 & 380,9 & - & 122,1 & 2,6 & 505,6 \\
\hline
\end{tabular}

*Número da campanha

* Contribuição técnica ao $44^{\circ}$ Seminário de Redução de Minério de Ferro e Matérias-primas, 15ㅇ Simpósio Brasileiro de Minério de Ferro e 2o Simpósio Brasileiro de Aglomeração de Minério de Ferro, 15 a 18 de setembro de 2014, Belo Horizonte, MG, Brasil. 


\section{MATERIAIS E MÉTODOS}

\subsection{Degradação e Reparo da Parede Refratária}

A partir de 2007, em inspeções rotineiras passaram a ser constatadas várias quedas de material refratário do Regenerador 7. Este material era originário da região acima do queimador cerâmico. Em 2010, foi iniciada a inspeção por vídeoendoscopia, e devido à grande deterioração da região onde se concentravam as quedas de tijolos associada à postergação da reforma do Alto-Forno 3 , decidiu-se pelo reparo a quente desse regenerador.

\subsection{Planejamento e Reparo do Regenerador 7}

A metodologia utilizada para a recuperação refratária do Regenerador 7 do AltoForno 3 foi a técnica de reparo a quente. A empresa contratada para a execução desta atividade é a detentora da tecnologia para este tipo de atividade no mundo.

llustrados nas figuras de 1 a 6 , o escopo do projeto de reparo que abrangia os seguintes pontos:

- recuperação a quente da parede refratária da câmara de combustão (aproximadamente $1 \mathrm{~m}$ abaixo e $3 \mathrm{~m}$ acima do anel de saída do duto de ar quente);

- recuperação do duto de saída de ar quente, podendo ainda ser aplicado tijolo isolante;

- recuperação do anel da saída do duto de ar quente (margarida), e fiadas danificadas pelo queimador cerâmico;

- montagem de modelo para treinamento de equipe de montagem dos tijolos refratários;

- fornecimento do heat shield para proteção térmica da equipe de montagem durante a execução da recuperação refratária;

- desmontagem e montagem da válvula de ar quente, junta de expansão da linha de ar quente, e flange cego refrigerado na tubulação de ar quente;

- fabricação, fornecimento, montagem e desmontagem de dispositivos provisórios para isolamento do Regenerador 7; e,

- aquisição de elementos de montagens, juntas de vedação, mantas cerâmicas e materiais para recomposição das instalações.

O serviço completo de reparo do Regenerador 7 contemplou os fornecimentos dos materiais refratários e equipamentos eletromecânicos. As atividades para reparo do Regenerador 7 foram iniciadas no dia 14/03/13 e finalizadas no dia 09/04/2013.

No dia $14 / 03 / 13$, foi realizada a parada do Alto-Forno 3 para isolamento do Regenerador 7. Nesta atividade, foram estabelecidas as condições para operação deste alto-forno com apenas dois regeneradores, que foi iniciada no dia 15/03/13. Esta operação foi finalizada no dia 09/04/13, quando foi realizada a interligação do Regenerador 7 no sistema de aquecimento do ar soprado do Alto-Forno 3 e restabelecida a operação com três regeneradores em sequência.

\footnotetext{
* Contribuição técnica ao $44^{\circ}$ Seminário de Redução de Minério de Ferro e Matérias-primas, 15은 Simpósio Brasileiro de Minério de Ferro e 20 Simpósio Brasileiro de Aglomeração de Minério de Ferro, 15 a 18 de setembro de 2014, Belo Horizonte, MG, Brasil.
} 


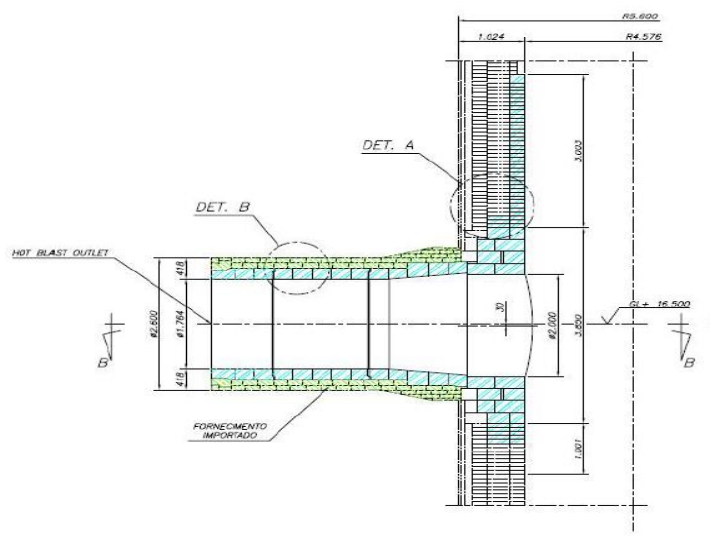

a) câmara de combustão

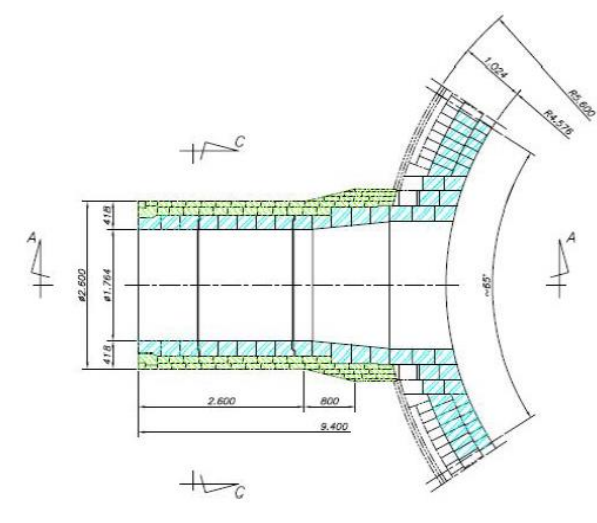

b) duto de saída de ar quente

Figura 1. Recuperação refratária das regiões desgastadas.

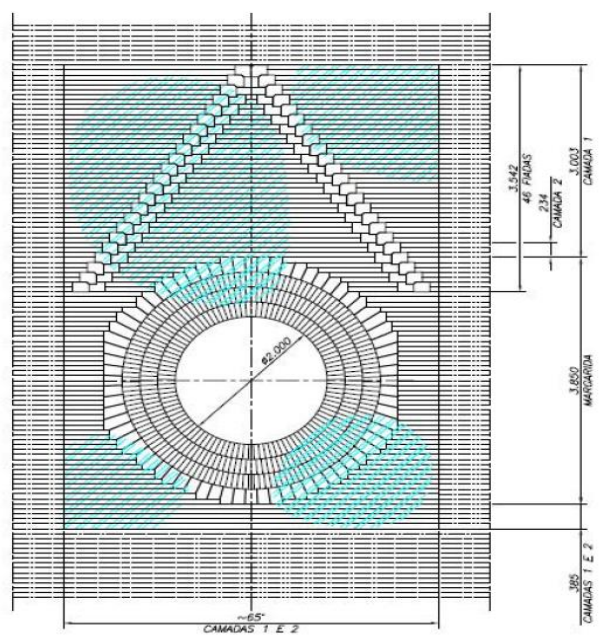

a) margarida
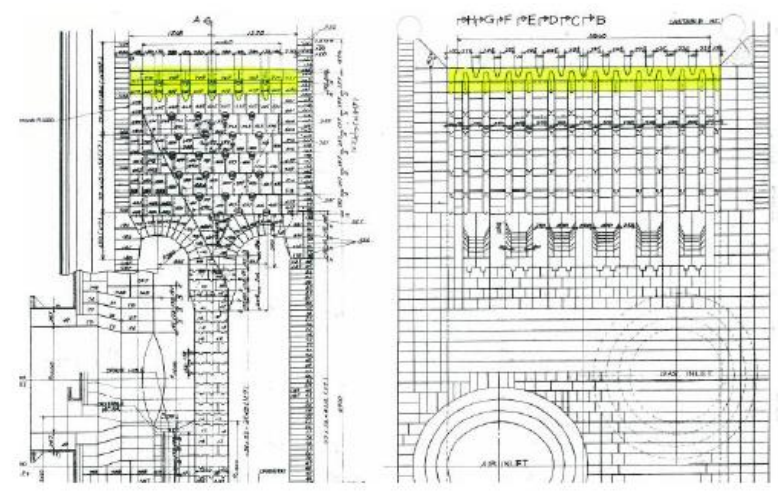

b) queimador cerâmico

Figura 2. Recuperação refratária. 


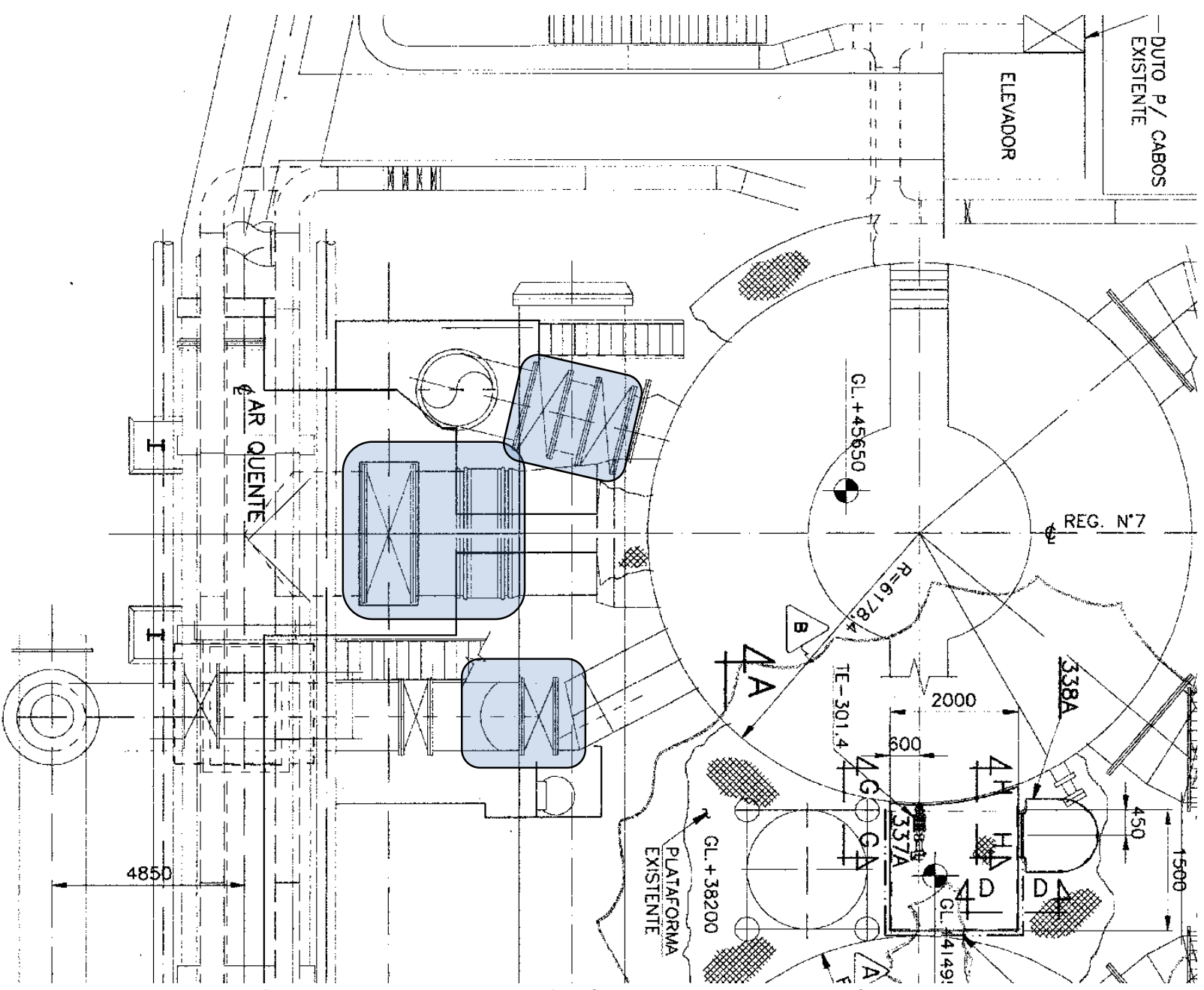

Figura 3. Recuperação refratária serviços eletromecânicos.
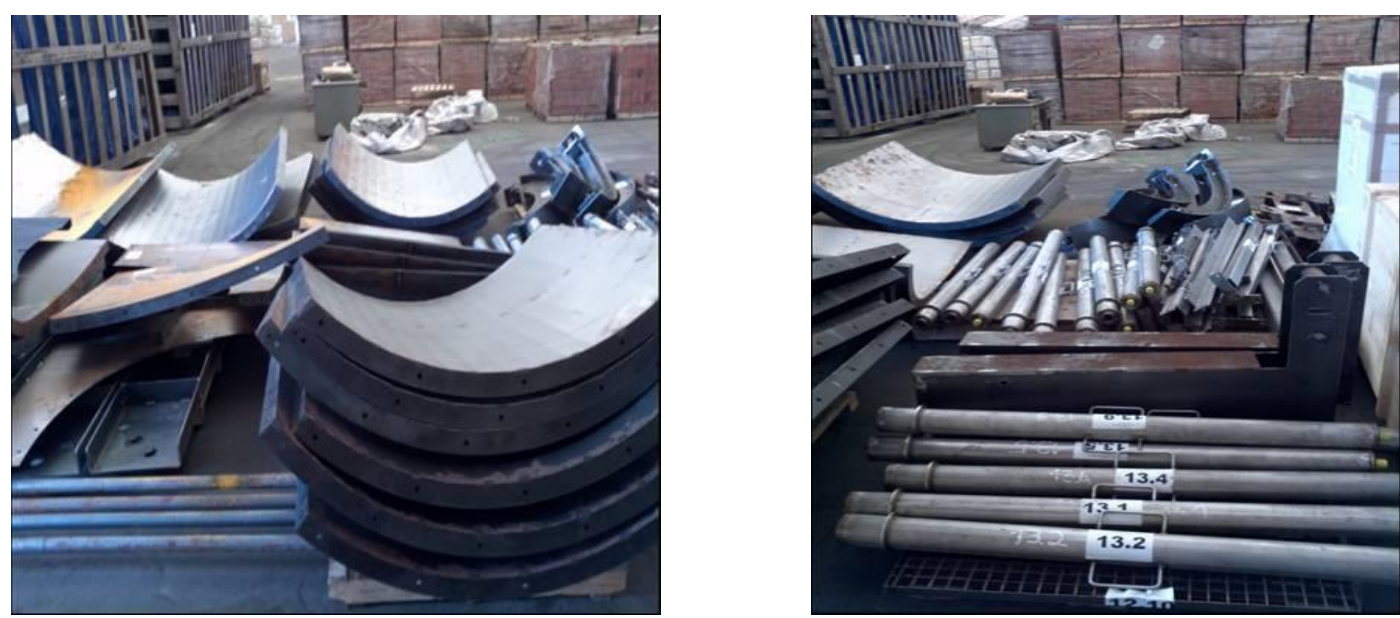

Figura 4. Materiais para montagem do modelo de treinamento das equipes.

* Contribuição técnica ao $44^{\circ}$ Seminário de Redução de Minério de Ferro e Matérias-primas, 15ํ Simpósio Brasileiro de Minério de Ferro e 2o Simpósio Brasileiro de Aglomeração de Minério de Ferro, 15 a 18 de setembro de 2014, Belo Horizonte, MG, Brasil. 

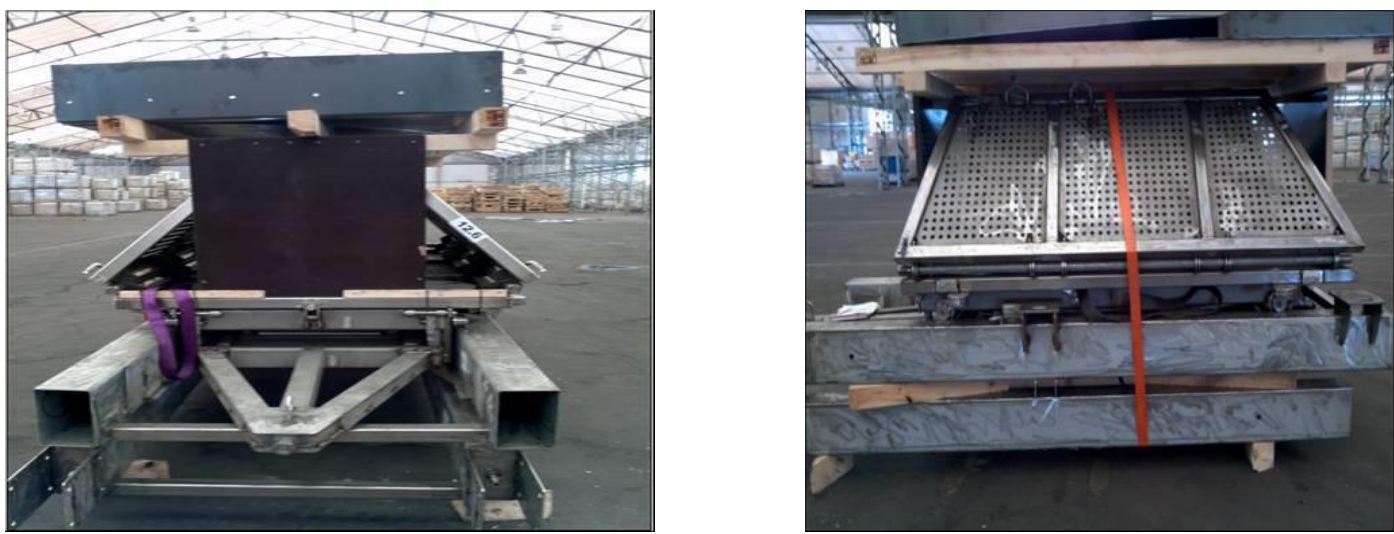

Figura 5. Heat shield.
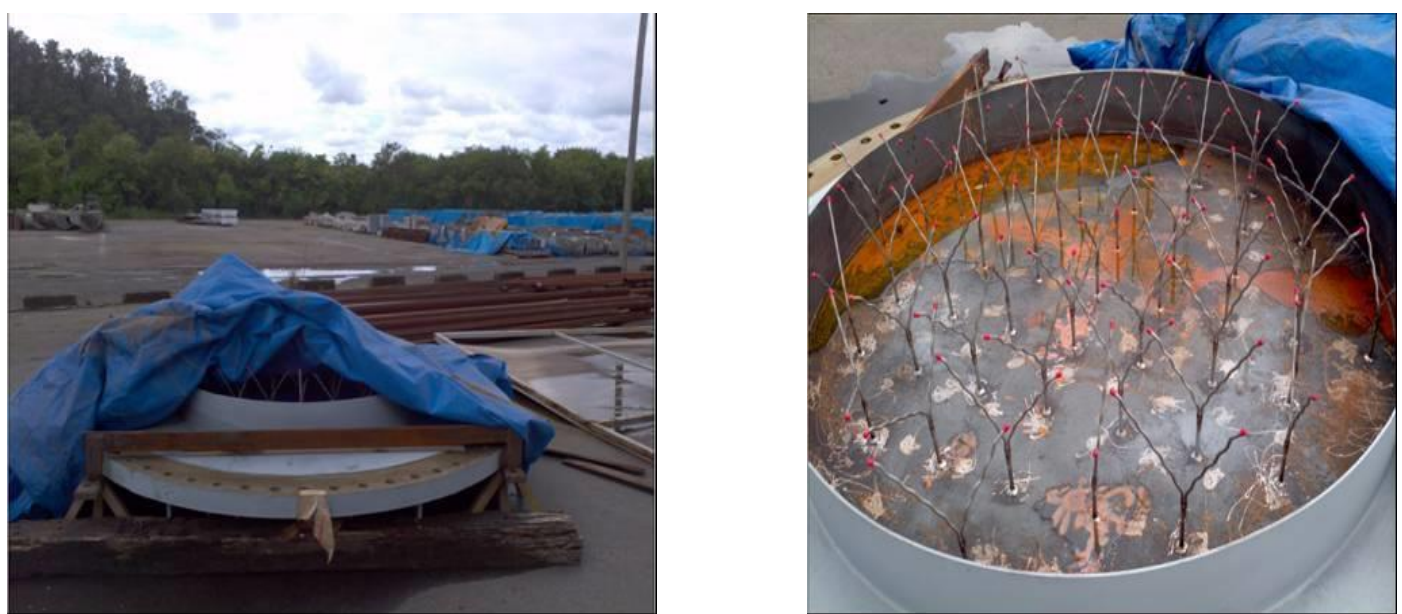

Figura 6. Flange refrigerado para isolamento provisório do Regenerador 7.

\subsection{Planejamento de Operação Durante o Reparo do Regenerador 7}

A operação do Alto-Forno 3, durante o reparo do Regenerador 7, foi realizada somente com dois regeneradores. Portanto, foram estabelecidos: os parâmetros operacionais, a estimativa de produção e o consumo de combustíveis durante este período.

As informações foram estimadas e estabelecidas a partir de dados históricos de 1994, quando o Alto-Forno 3 operou com dois regeneradores por um período de aproximadamente três dias.

Os parâmetros operacionais estimados estão na tabela 3.

* Contribuição técnica ao 44 Seminário de Redução de Minério de Ferro e Matérias-primas, $15^{\circ}$ Simpósio Brasileiro de Minério de Ferro e $2^{\circ}$ Simpósio Brasileiro de Aglomeração de Minério de Ferro, 15 a 18 de setembro de 2014, Belo Horizonte, MG, Brasil. 
Tabela 3. Valores de operação estimados e estabelecidos durante o reparo do Regenerador 7

\begin{tabular}{l|l}
\hline \multicolumn{2}{c}{ Parâmetros operacionais } \\
\hline Produção (t/d) & 6400 \\
\hline Vazão de ar $\left(\mathrm{Nm}^{3} / \mathrm{min}\right)$ & 4400 \\
\hline Vazão de oxigênio $\left(\mathrm{Nm}^{3} / \mathrm{h}\right)$ & 14000 \\
\hline Pressão de base $\left(\mathrm{g} / \mathrm{cm}^{2}\right)$ & 2890 \\
\hline Pressão de topo $\left(\mathrm{g} / \mathrm{cm}^{2}\right)$ & 1430 \\
\hline Temperatura do ar $\left({ }^{\circ} \mathrm{C}\right)$ & 900 \\
\hline Injeção de PCl $(\mathrm{kg} / \mathrm{t})$ & 0 \\
\hline Injeção de $\mathrm{GN}(\mathrm{kg} / \mathrm{t})$ & 30 \\
\hline Minério/Coque $(-)$ & 3,40 \\
\hline Coke-Rate $(\mathrm{kg} / \mathrm{t})$ & 489,0 \\
\hline Fuel-Rate $(\mathrm{kg} / \mathrm{t})$ & 519,0 \\
\hline Small-Rate $(\mathrm{kg} / \mathrm{t})$ & 12,0 \\
\hline Slag-Rate $(\mathrm{kg} / \mathrm{t})$ & 325,0 \\
\hline \multicolumn{2}{|l}{ Carga metálica $(\%)$} \\
\hline Sinter & 84 \\
\hline Minério Granulado & 16 \\
\hline Pelota & 0 \\
\hline
\end{tabular}

A operação do Alto-Forno 3 com dois regeneradores estava de acordo com os procedimentos operacionais de controle de combustão, rotina de equalização de alívio de pressão e padrão de operação. Havia vários pontos a serem observados durante este período, dentre os quais se destacam:

- realizar a parada emergencial do Alto-Forno 3 em caso de falha de um dos regeneradores em operação;

- evitar a entrada no ciclo de ventilação em paralelo dos dois regeneradores em operação para não se perder tempo no ciclo de combustão. Foi criado alarme no supervisório para alertar sobre esta ocorrência;

- realizar ciclo de ventilação dos regeneradores estimado em 50 minutos; e,

- priorizar o atendimento pelas equipes de manutenção nas ocorrências envolvendo os regeneradores em operação.

\section{RESULTADOS E DISCUSSÃO}

\subsection{Parâmetros Operacionais Alcançados Durante Período de Reparo}

Os valores dos parâmetros operacionais alcançados, neste período de reparo do Regenerador 7, foram melhores em relação aos valores planejados. A seguir, nas figuras 7 a 11, são apresentados os acompanhamentos destes parâmetros e consumos estimados para o período de reforma do regenerador.

\footnotetext{
* Contribuição técnica ao $44^{\circ}$ Seminário de Redução de Minério de Ferro e Matérias-primas, 15ํ Simpósio Brasileiro de Minério de Ferro e $2^{\circ}$ Simpósio Brasileiro de Aglomeração de Minério de Ferro, 15 a 18 de setembro de 2014, Belo Horizonte, MG, Brasil.
} 


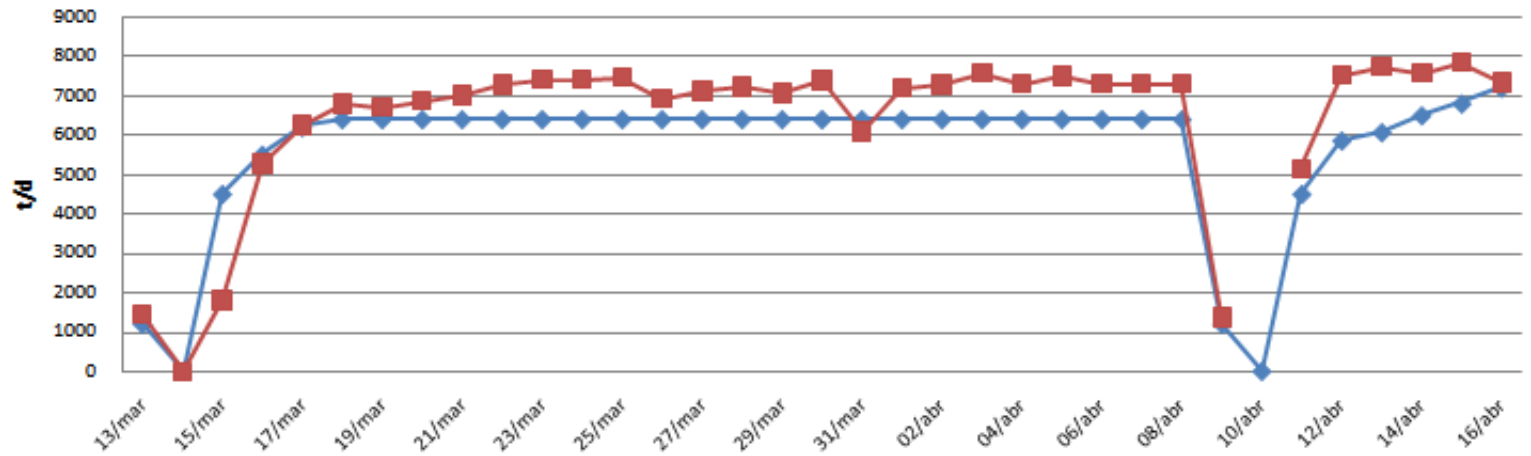

Figura 7. Produção planejada e produção atingida nos períodos de preparação, execução e recuperação após o reparo do Regenerador 7 .

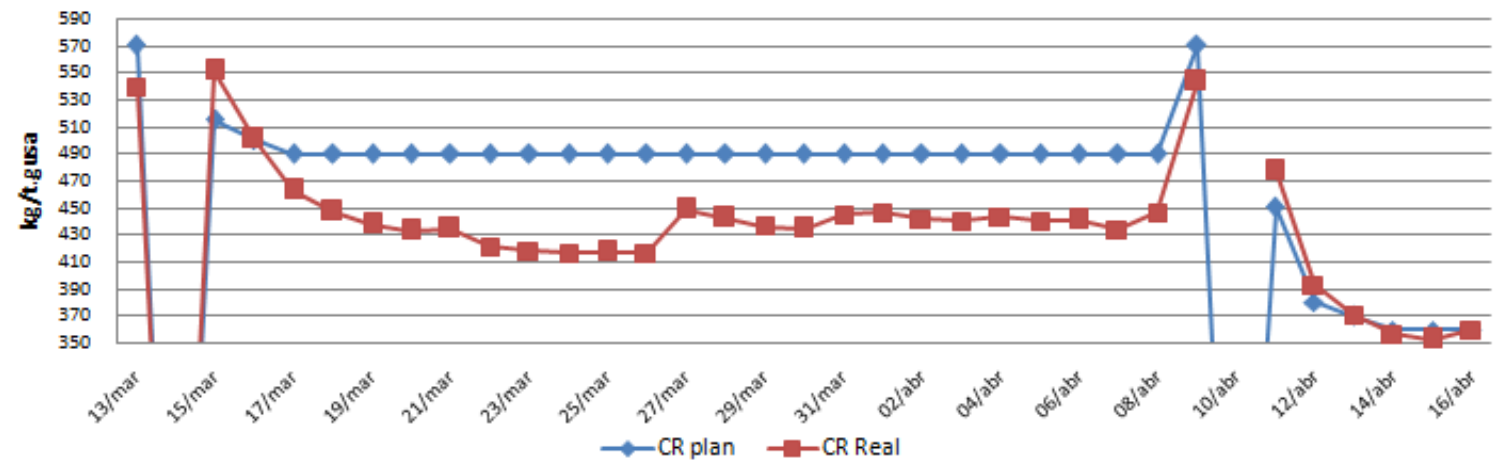

Figura 8. Coke rate planejado e coke rate atingido nos períodos de preparação, execução e recuperação após o reparo do Regenerador 7 .

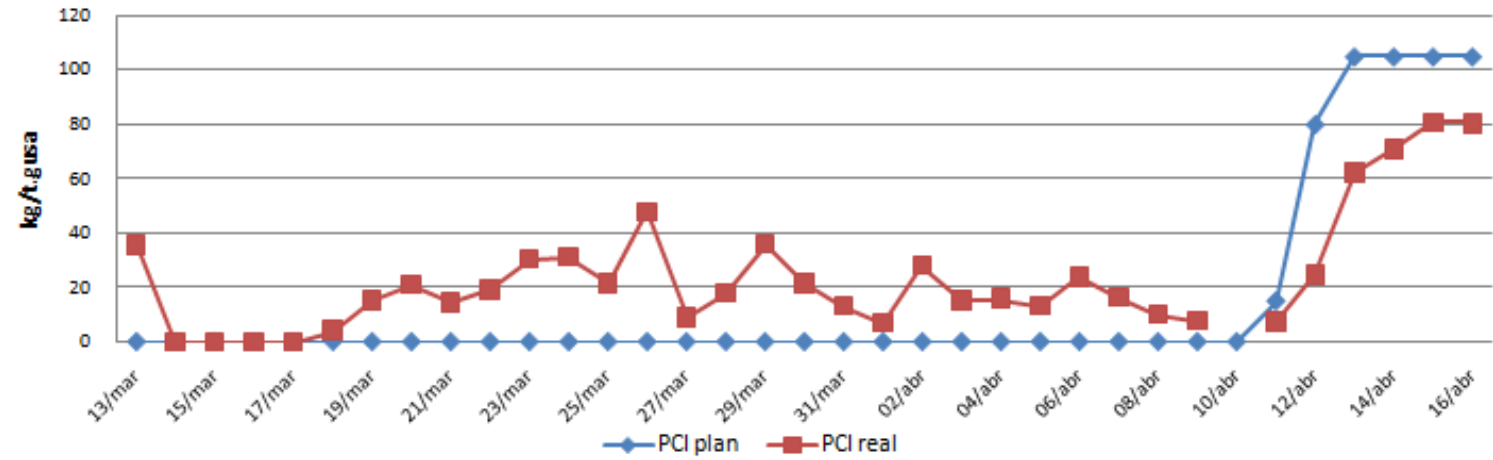

Figura 9. Coal rate planejado e coal rate alcançado nos períodos de preparação, execução e recuperação após o reparo do Regenerador 7.

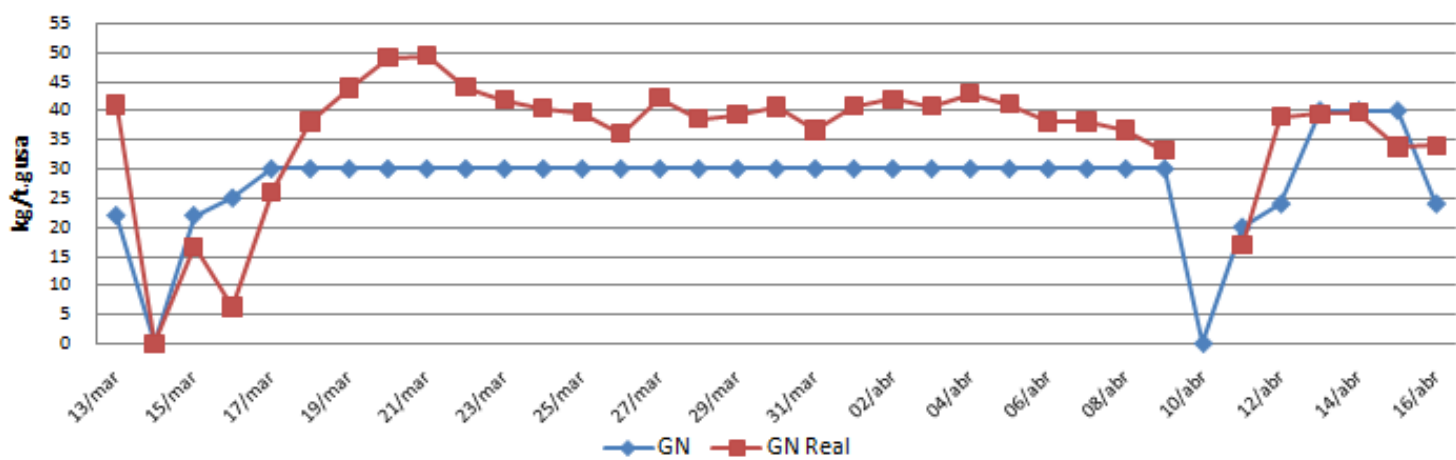

Figura 10. Gas rate planejado e gas rate alcançado nos períodos de preparação, execução e recuperação após o reparo do Regenerador 7.

* Contribuição técnica ao 44 Seminário de Redução de Minério de Ferro e Matérias-primas, 15은 Simpósio Brasileiro de Minério de Ferro e 20 Simpósio Brasileiro de Aglomeração de Minério de Ferro, 15 a 18 de setembro de 2014, Belo Horizonte, MG, Brasil. 


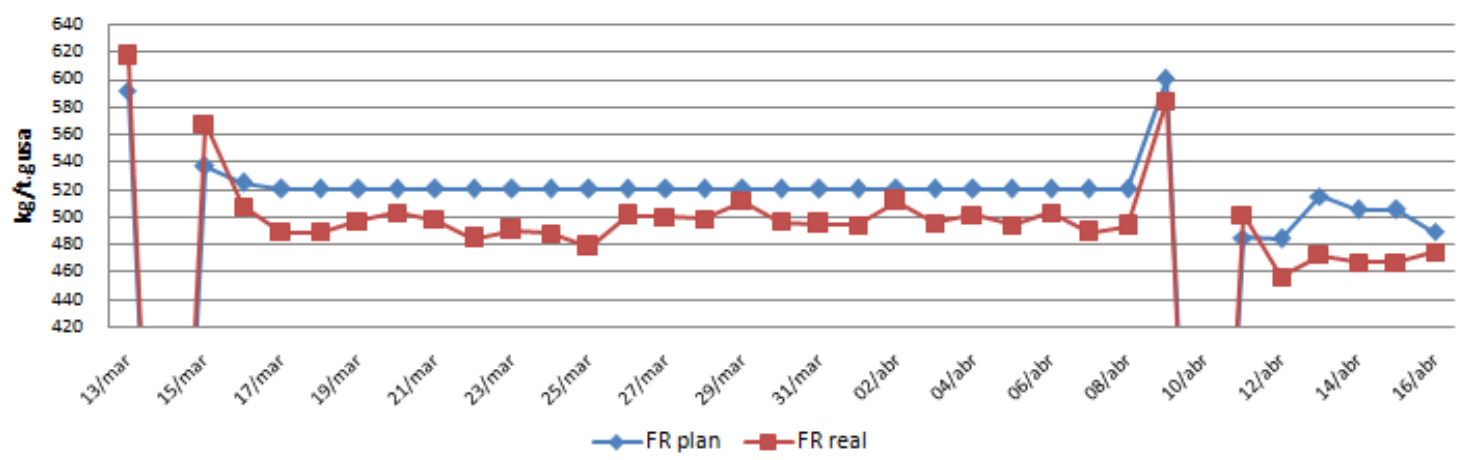

Figura 11. Consumo de combustíveis planejado e consumo de combustíveis alcançado nos períodos de preparação, execução e recuperação após o reparo do Regenerador 7.

Os resultados apresentados pelo Alto-Forno 3 durante este período mostraram que o equipamento respondeu positivamente às restrições previstas para operação com dois regeneradores. A superação das estimativas operacionais propostas evidenciou que os dados históricos utilizados não se aproximaram das condições operacionais atuais, sendo esta superação relacionada à evolução do processo produtivo que está sendo aprimorado no decorrer dos anos.

Os resultados operacionais posteriores ao reparo do Regenerador 7 mostraram que a recuperação refratária foi eficiente, pois o Alto-Forno 3 apresentou tendência de retornar aos patamares de operação anteriores às quedas de refratários do Regenerador 7. No entanto, outras interferências relacionadas ao tempo de campanha deste alto-forno interferiram na produção, consumo de combustíveis e parâmetros operacionais, prejudicando os resultados operacionais.

Nas atividades similares a serem executadas futuramente em outros regeneradores da Usiminas, as práticas operacionais de altos-fornos com dois regeneradores deverão ser executadas novamente. Portanto, todas estas informações e resultados obtidos na reforma do Regenerador 7 servirão como base para estimativas de produção, consumo de combustíveis e parâmetros operacionais porque são condições e parâmetros mais recentes e condizentes com a situação atual do processo produtivo.

\section{CONCLUSÃO}

Foi realizado, com grande sucesso, reparo a quente no Regenerador 7 do AltoForno 3 da Usiminas. Durante o período de manutenção, que compreendeu cerca de 20 dias, o Alto-Forno 3 operou com apenas dois regeneradores, apresentando excelentes resultados operacionais, superando a expectativa em termos de consumo de combustível e produção.

\section{REFERÊNCIAS}

1 Cota JM, Andrade JOC, Matos AE. - Metodologia de Reforma e Resultados das

Campanhas dos Altos-Fornos da Usiminas - Siderurgia Latino-Americana - no 343;

Novembro de 1988.

* Contribuição técnica ao 44 Seminário de Redução de Minério de Ferro e Matérias-primas, 15ํ Simpósio Brasileiro de Minério de Ferro e $2^{\circ}$ Simpósio Brasileiro de Aglomeração de Minério de Ferro, 15 a 18 de setembro de 2014, Belo Horizonte, MG, Brasil. 